Fordham University

Fordham Research Commons

\title{
Senior Centers and Policy Advocacy: Changing Public Perceptions
}

\author{
Manoj G. Pardasani \\ Adelphi University \\ Lauri Goldkind \\ Fordham University
}

Follow this and additional works at: https://research.library.fordham.edu/gss_facultypubs

Part of the Social Work Commons

\section{Recommended Citation}

Pardasani, Manoj G. and Goldkind, Lauri, "Senior Centers and Policy Advocacy: Changing Public Perceptions" (2012). Social Service Faculty Publications. 15.

https://research.library.fordham.edu/gss_facultypubs/15

This Article is brought to you for free and open access by the Graduate School of Social Service at Fordham Research Commons. It has been accepted for inclusion in Social Service Faculty Publications by an authorized administrator of Fordham Research Commons. For more information, please contact considine@fordham.edu, bkilee@fordham.edu. 
This article was downloaded by: [Fordham University]

On: 25 January 2014, At: 11:57

Publisher: Routledge

Informa Ltd Registered in England and Wales Registered Number: 1072954 Registered office: Mortimer House, 37-41 Mortimer Street, London W1T 3J H, UK

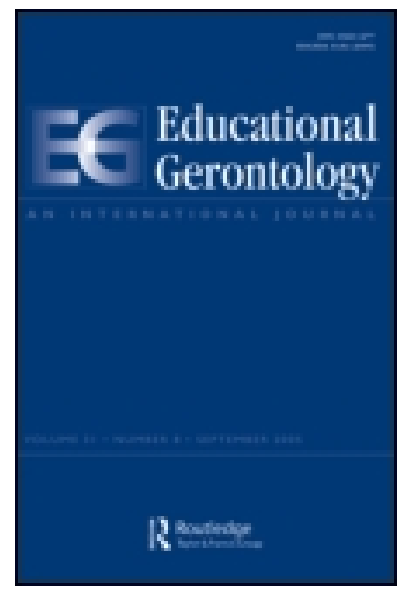

\title{
Educational Gerontology
}

Publication details, including instructions for authors and subscription information:

http:// www.tandfonline.com/loi/ uedg20

\section{Senior Centers and Policy Advocacy: Changing Public Perceptions}

\author{
Manoj Pardasani ${ }^{a} \&$ Lauri Goldkind ${ }^{\text {a }}$ \\ a Graduate School of Social Service, Fordham University, New York , \\ New York, USA \\ Published online: 27 Mar 2012.
}

To cite this article: Manoj Pardasani \& Lauri Goldkind (2012) Senior Centers and Policy Advocacy: Changing Public Perceptions, Educational Gerontology, 38:6, 375-390, DOI: 10.1080/03601277.2010.544588

To link to this article: http:// dx. doi.org/ 10.1080/03601277.2010.544588

\section{PLEASE SCROLL DOWN FOR ARTICLE}

Taylor \& Francis makes every effort to ensure the accuracy of all the information (the "Content") contained in the publications on our platform. However, Taylor \& Francis, our agents, and our licensors make no representations or warranties whatsoever as to the accuracy, completeness, or suitability for any purpose of the Content. Any opinions and views expressed in this publication are the opinions and views of the authors, and are not the views of or endorsed by Taylor \& Francis. The accuracy of the Content should not be relied upon and should be independently verified with primary sources of information. Taylor and Francis shall not be liable for any losses, actions, claims, proceedings, demands, costs, expenses, damages, and other liabilities whatsoever or howsoever caused arising directly or indirectly in connection with, in relation to or arising out of the use of the Content.

This article may be used for research, teaching, and private study purposes. Any substantial or systematic reproduction, redistribution, reselling, loan, sub-licensing, systematic supply, or distribution in any form to anyone is expressly forbidden. Terms \& Conditions of access and use can be found at http://www.tandfonline.com/page/termsand-conditions 


\title{
Senior Centers and Policy Advocacy: Changing Public Perceptions
}

\author{
Manoj Pardasani and Lauri Goldkind \\ Graduate School of Social Service, Fordham University, New York, New York, USA
}

\begin{abstract}
As critical components of the aging continuum of care, senior centers promote older adult health and well-being by providing opportunities for recreation, socialization, nutrition, health education, and access to vital social services. Nationally, a vast network of 11,000 senior centers serves over four million older adults annually. As the United States population ages rapidly, public funding, which is the primary source of support for a majority of senior center services, has remained stagnant. If senior centers are to continue to effectively serve older adults and meet their comprehensive needs, they need to demonstrate their relevance to the community and advocate for increased funding support. This paper explores the policy concerns of senior center administrators, investigates their efforts to influence public policy, illustrates advocacy techniques currently utilized by them, and highlights the learning needs of administrators in this regard. Practice implications for senior centers, their constituents, and gerontological education are provided.
\end{abstract}

With the exponential growth in the senior population, senior centers have gained a prominent role in the provision of services for older adults (Aday, 2003b; Krout, 1998; Pardasani, 2004a, $2004 b, 2004 c)$. Senior centers are an integral component of the continuum of long-term care, allowing older adults to retain their independence and self-reliance for the longest extent possible (Administration on Aging [AoA], 2010; Krout, 1998; Leanse \& Wagener, 1975; Leest, 1995). They play a critical role in community-based services for older adults by providing opportunities for recreation, socialization, volunteer development, information and referral, advocacy, education, outreach, nutrition, and health promotion (Aday, 2003a, 2003b; Harris \& Associates, 1975; Krout, 1982, 1988, 1994, 1998; National Institute of Senior Centers [NISC], 2010; Pardasani, Sackman, \& Jellinek, 2010; Strain, 2001).

The National Institute of Senior Centers (NISC, 2010) reports that there are currently 11,000 senior centers serving older adults in the U.S. Krout (1998) and NISC (2010) estimate that nearly four to five million senior citizens utilize a senior center program or service annually. These statistics confirm the relevance of senior centers to the aging network.

The authors would like to acknowledge Marietta Bobba, Howard Bedlin, and Jim Firman of the National Council on Aging (NCOA) for their pioneering work in public policy analysis and advocacy. They are tireless advocates for older adults and their social safety nets. This study was the brainchild of Marietta and Howard, and we would like to thank them for their guidance and commitment.

Address correspondence to Manoj Pardasani, Associate Professor, Graduate School of Social Service, Fordham University, 113 West 60th Street, Room \#719-F, New York, NY 10023. E-mail: mpardasani@fordham.edu 


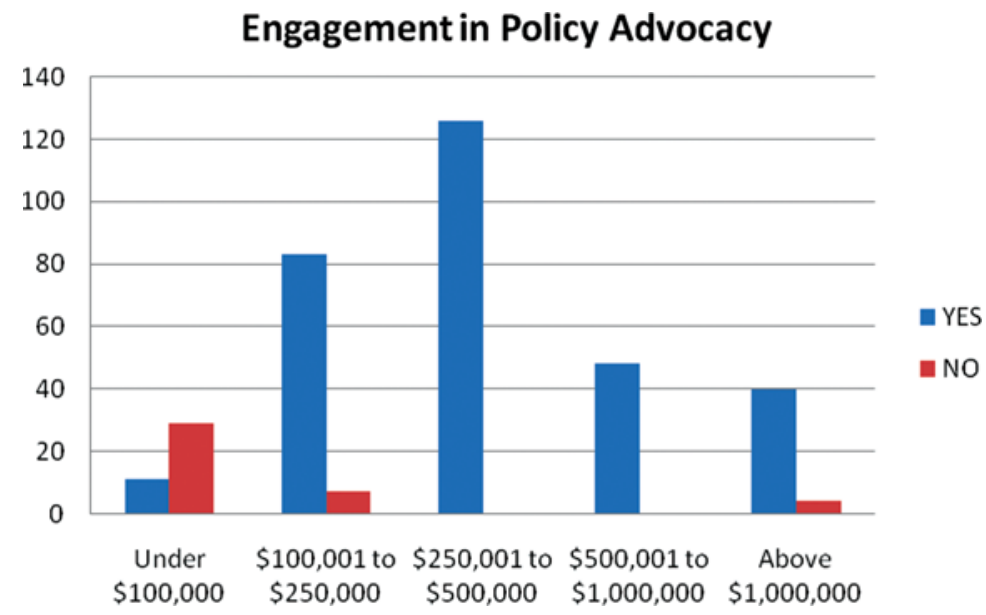

FIGURE 1 Engagement in policy advocacy. (Color figure available online.)

\section{PURPOSE}

Senior centers offer a diverse array of services and programs to meet the needs of independent older adults (Calsyn \& Winter, 1999; Demko, 1979; Harris \& Associates, 1975; Lun, 2004; Mitchell, 1995; Netzer et al., 1997; Ralston 1982, 1983, 1984, 1991; Tuckman, 1967). Senior centers, depending on their size, budget, and programmatic focus, may range in scope from recreational clubs or nutrition sites, to traditional community-based senior centers and large, multipurpose senior centers. This diversity makes it difficult to characterize them into specific service models (Pardasani, 2004c; Pardasani, Thompson, \& Sporre, 2009). They are usually supported and frequently directly operated by the Area Agencies of Aging, municipal governments, offices of aging (state and city), or the parks and recreation departments (Krout, 1998; NISC, 2010; National Council on Aging [NCOA], 2010a).

Despite the significant growth in the senior population, funding for senior centers has remained stagnant. This is cause for concern among senior center administrators who are faced with increasing operating costs (NCOA, 2010a; Pardasani et al., 2009; Pardasani, 2010; Pardasani et al., 2010). Given the current state of the economy, government and philanthropic support has diminished substantially, thereby negatively impacting senior centers ability to continue offering a vibrant array of services (The Center on Philanthropy at Indiana University, 2010; NCOA, 2010a). In this environment, senior centers have had to advocate vociferously for their share of public funding support and attention. Furthermore, senior center administrators have expressed a need for best-practice models of effective policy advocacy in order to effectively strategize their efforts.

The purpose of this study was to understand how senior center administrators are navigating a highly competitive funding environment and to identify what, if any, advocacy strategies they are utilizing to help solidify their place in their communities. This study, initiated by the National Institute of Senior Centers (NISC), surveyed senior centers across the United States to explore the policy concerns of senior center administrators, investigate their efforts to influence public 


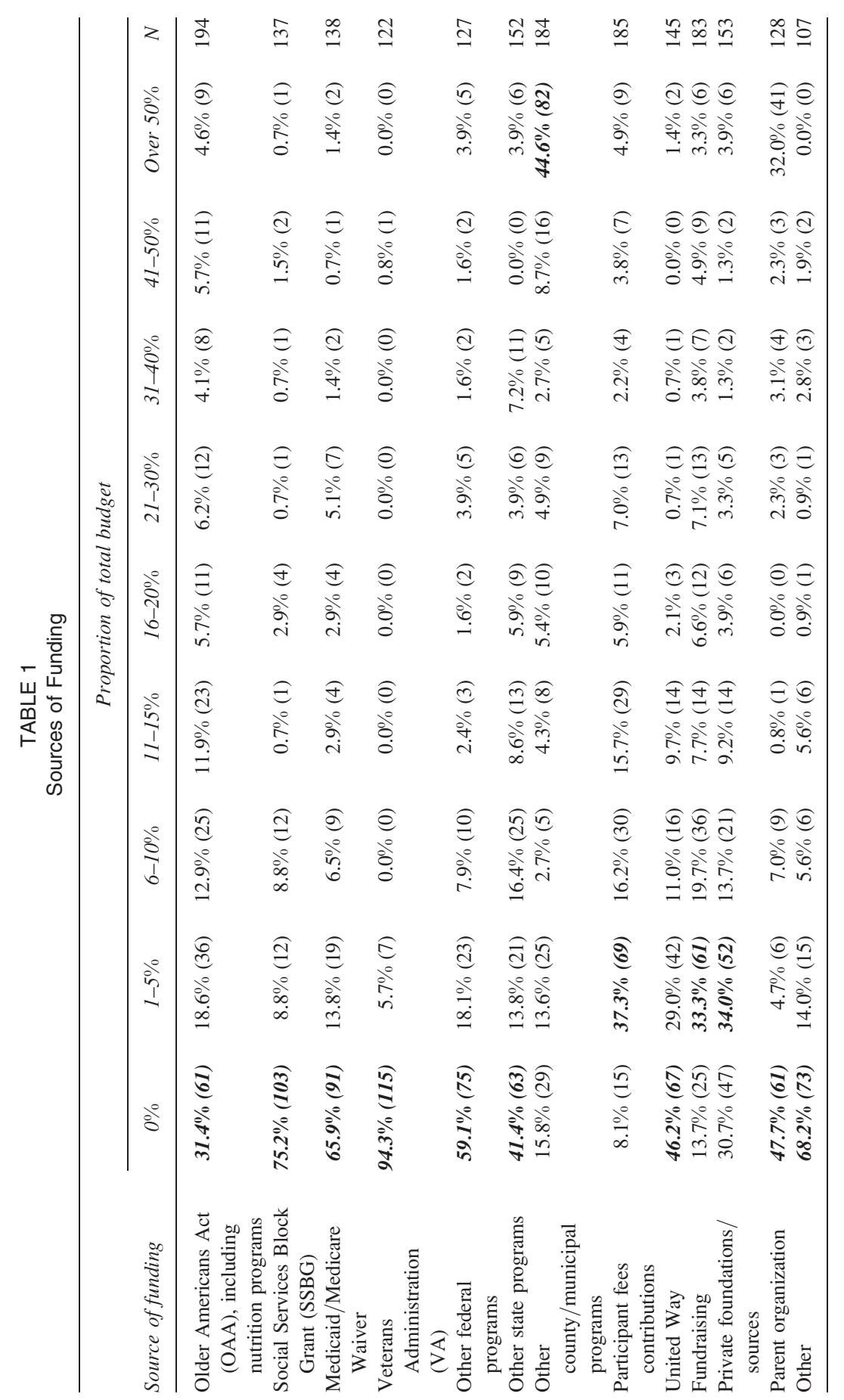


policy, illustrate advocacy techniques currently utilized by them, and highlight the learning needs of administrators in this regard. Research in this area is important to informing the survival of senior center networks.

\section{LITERATURE REVIEW}

One of the most pressing issues facing senior centers is the developmental needs of administrators to effectively advocate for resources in a scarce-funding climate. Understanding the need for advocacy strategies, current policies with reference to aging and senior centers, and effective techniques to advance policy agendas, is critical to ensuring that senior centers continue to promote the health and well being of community-dwelling older adults. This literature review incorporates the current definitions of policy advocacy, highlights effective advocacy techniques identified by researchers, and provides background information on the funding structure and public policies that govern the operation of most senior centers.

\section{Definition of Policy Advocacy}

Advocacy is defined as "the act of directly representing, defending, intervening, supporting, or recommending a course of action [for and with a population] with the goal of securing or retaining social justice", (Mickelson, 1995, p. 95). These activities include organizing, convening, analyzing, educating, interviewing, researching, mobilizing, writing, and disseminating (Donaldson, 2007). Avner (2002) defined advocacy broadly as "an effort to shape public perception or to effect change that may or may not require changes in the law" (p. 26).

\section{Policy Advocacy Techniques}

Utilizing Schneider and Lester's (2001) core dimensions of policy advocacy behavior, Donaldson and Shields (2009) identified four important components of effective policy advocacy: speaking out on behalf of others, utilizing mass strategies for consciousness raising (such as protests, vigils, letter-writing, e-mails, etc.), cultivating relationships with decision makers and influential actors, developing collaborations with constituents, and empowering those impacted by the policies. Describing the development of a training curriculum for advocates in aging, Baker, Leitner and McAuley (2001) highlighted the importance of current knowledge of aging and policy issues, communication skills, awareness of policy development, and processes to the learning needs for effective policy advocacy. They also emphasized practical skills such as engaging the media, writing policy briefs, developing talking points, and conducting successful negotiations.

Researchers have also found that organizational characteristics and leadership styles were significantly related to effective policy advocacy. With respect to organizational characteristics, Donaldson and Shields (2009) found that staff size, organizational budget, and proportion of public funding were all positively correlated with increased advocacy behavior. De Vita, Montilla, Reid, and Fatiregun (2004) found that organizational structures, financial resources, good leadership, and active constituencies were essential contributors to effective advocacy 
practice. De Vita, Mosher-Williams, and Stengel (2001) posit that the larger the agency (in terms of manpower, resources and budget), the greater its commitment to sustained advocacy efforts.

Leadership is also a critical factor for engagement in policy advocacy (Cohen, 2004; Donaldson, 2007; Donaldon \& Shields, 2009). Researchers have found that the level of knowledge of the leader, their vision for the organization and policy issues, as well as their commitment to social change play a significant role in successful advocacy efforts (Donaldson \& Shields, 2009; Gibelman \& Kraft, 1996; Salamon, 1995; Saidel \& Harlan, 1998).

\section{Aging and Policy Advocacy}

The United States population of people 65 and older presently stands at 38.9 million and is expected to nearly double to 70 million by 2030 (U.S. Census Bureau, 2010). As of 2030, one in every five U.S. residents will be over the age of 65 , and one in three will be over the age of 50 (U.S. Census Bureau, 2010). With an exploding population of older adults will come increased needs for critical social, mental health, and healthcare services. As mentioned above, public funding for aging programs has not kept pace with this rapidly changing scenario (NCOA, 2009). Organizations serving older adults must compete for resources with organization serving other constituencies while simultaneously vying for this limited pool of public funding (Pardasani, 2010).

On a national level, the National Council of Aging (NCOA), the National Association of the State Units of Aging (NASUA), and the National Association of the Area Agencies on Aging (NAAAA), have been active in advocating for the needs of community-based aging services and senior centers (AoA, 2010; NASUA, 2008). The National Institute of Senior Centers (NISC), a partner constituent organization of the NCOA, is a senior center membership and policy advocacy organization that advocates solely for the needs and benefits of senior centers. However, its membership is not currently reflective of the vast national senior center network, and hence, its overall impact is limited.

At the state and regional levels, only 20 states have associations of senior centers, and some counties have informally created coalitions of senior center providers (NISC, 2010). Each group is concerned about the sustainability of their own constituency, and as a result, broader coalitions are rare.

\section{Senior Center Funding}

The Older Americans Act (OAA) is the single most important piece of federal legislation that provides for the support and operations of senior centers, as well as other community-based services for older adults (AoA, 2000; NCOA, 2009, 2010a). The allocations are distributed among the states based on several factors including the concentration of residents over the age of 65 . States, counties, and municipal governments then supplement these OAA funds to help support the network of aging providers in their jurisdictions. However, the allocations at the regional and local levels are widely disparate and depend on local priorities and environmental contexts (Pardasani, 2004c).

OAA funding provides money for supportive services, congregate nutrition services (meals served at group sites such as senior centers, community centers, schools, churches, or senior 
housing complexes); home-delivered nutrition services; community service employment; the long-term care ombudsman program; and services to prevent the abuse, neglect, and exploitation of older persons. The total allocation in 2009 for the Older Americans Act was \$2.06 billion, of which approximately $\$ 380$ million was allocated to community-based services (Congressional Research Services [CRS], 2008; NCOA, 2010b). If we assume that there are of 39 million people over the age of 65 , this allocation for community-based services (which includes home-based services such as home-health care, health assessments, access and transportation services, as well as senior centers) works out to less than $\$ 10$ per older adult person per year (U.S. Census Bureau, 2010). When meal program allocations are added to this budget, the allocation rises to approximately $\$ 27.33$ per older adult person per year (for all community-based services including meals).

Assuming that only $25 \%$ of the older adult population would be in need of senior center programs, services, or meals, the total federal expenditure per person just towards a senior center works out to approximately $\$ 40$ per year. This per capita allocation is woefully inadequate and incapable of supporting senior centers at their current levels of functioning. The National Council on Aging (2009) reports that if funding for senior centers and other supportive services had kept pace with inflation, the current appropriation for this program would be $\$ 707,000,000$, nearly twice that which it is currently budgeted for.

The literature reviewed suggests that there is limited information on the current practices, knowledge, needs, and concerns of senior center administrators with respect to policy advocacy. The following research questions guided the study:

1. What are the policy concerns of senior center administrators?

2. How do senior center administrators engage in policy advocacy?

3. What is the current state of coalitions and collaborations within the aging network with respect to advocacy?

4. What are the learning and development needs of senior center administrators?

\section{METHODOLOGY}

\section{Study Design}

To answer the research questions described above, an exploratory study was conducted. This study sought the opinions and perspectives of senior center administrators in the United States. Respondents were reached through a purposive, nonrandom, nonprobability, sampling of senior center directors. An e-mail with a link to the electronic survey was sent out to all 751 members of the National Institute of Senior Centers (NISC), a national advocacy and membership organization. In order to diversify the sample and reach out to nonmembers, invitations for participations were sent to 20 state associations of senior centers, of which, 9 agreed to forward the survey to their members (Connecticut, Maryland, Massachusetts, Michigan, Minnesota, Ohio, Pennsylvania, Florida, and Indiana). Since there is no single database for senior centers, this sampling method was the most efficient and feasible mechanism for reaching the target population. Approximately 1,200 senior centers were invited to participate. The final sample comprised 376 senior center administrators (including 27 Area Agencies on Aging [AAAs]), yielding a response rate of $31.25 \%$. 


\section{Survey Instrument}

The survey instrument (The Senior Center Policy Practice Survey) was developed by the author in conjunction with a Policy Survey Advisory Committee that comprised two administrators of the policy and advocacy division at NISC, three senior center administrators, and the author. The survey instrument was piloted with 10 respondents (senior center administrators) for ease of language, length, clarity, time required for completion, and internal validity. The survey contained 28 questions (4 questions had 3 subsections) that assessed the organizational characteristics of the respondents (with reference to source and scope of funding), policy advocacy techniques utilized by senior center administrators, and their policy concerns.

\section{Data Collection}

The survey instrument was administered in an electronic format on Survey Monkey. It was estimated that the self-administered survey would take 20-30 minutes to complete. The advisory committee drafted a cover letter (sent via e-mail) explaining the purpose and rationale for the study. That e-mail provided a link that directed potential respondents to the survey.

\section{Sample}

The sample was comprised of 376 senior center administrators, the majority of whom represent multipurpose senior centers $(N=271,72.1 \%)$. The other two types of organizations represented in the sample were Nutrition Sites (usually smaller senior centers with very limited programming) $(N=76,20.2 \%)$ and Area Agencies on Aging $(N=27,7.2 \%)$. The respondents were located in 39 states. Most of the respondents were located in the following states: Connecticut, Maryland, Massachusetts, Michigan, Minnesota, Ohio, Pennsylvania, Texas, and Washington. More than half the respondents $(N=207,55 \%)$ were members of their respective state associations of senior centers. About five respondents identified themselves as County or State Offices of Aging that operated senior centers. The annual budgets ranged from $\$ 26,725$ (Nutrition Site) to $\$ 250$ million (State Office on Aging). The largest proportion of budgets ranged between $\$ 100,000$ and $\$ 750,000$. There were a few respondents that listed their budgets between $\$ 1$ million and $\$ 5$ million. Only one respondent listed their budget as \$100 million (County Office on Aging).

\section{FINDINGS}

Although Area Agencies on Aging were a part of the study sample, the focus of this article is on senior centers. Hence, AAAs have been excluded from the following discussion, which only describes the policy advocacy efforts and concerns of senior centers and nutrition sites (collectively referred to here as senior centers).

\section{Engagement in Policy Advocacy}

An overwhelming majority of senior center administrators $(N=308,88.5 \%)$ reported that they engaged in some form of policy advocacy efforts. Only 40 administrators $(11.5 \%)$ reported that 
they do not engage in any advocacy efforts. Senior centers with larger budgets (higher than $\$ 250,000$ ) and those heavily dependent on public funding were most likely to engage in advocacy efforts.

Even though some senior centers collaborate with other providers on policy advocacy, the most common reason given by senior center administrators for engaging in advocacy was related to funding issues for senior center programs and services $(63.2 \%, N=220)$. The most critical policy issues related to community-based aging services, as highlighted by senior center administrators, were funding issues related to services affecting the older adults, OAA allocations, lack of accessible and affordable transportation, healthcare, Medicare and health insurance costs, concerns over Social Security benefits and the availability of long-term care and home-healthcare. With respect to specific senior center issues, more than two-thirds of the senior centers identified facility maintenance $(71.8 \%, N=250)$ and budget support for operations $(69.3 \%, N=241)$ as significant areas for concern. More than half of all senior centers respondents identified transportation costs $(55.4 \%, N=193)$ and meal provision costs, a core service of senior centers $(50.8 \%, N=177)$, as critical policy concerns.

When asked to highlight the barriers to engagement in policy advocacy as perceived by administrators, the most common barriers cited were lack of knowledge or clarity on current policy issues $(61.5 \%, N=214)$, lack of experience in policy advocacy $(55.7 \%, N=194)$, and a perceived lack of support for advocacy efforts from funding sources $(52 \%, N=181)$. In the comments section of the survey, a large number of respondents stated that they had received limited education/training on policy advocacy and that most had learned how to advocate through personal trial and error. Over one third of all senior center administrators $(37.1 \%$, $N=129$ ) feared that engaging in advocacy would alienate their funders (local and regional departments) and have negative repercussions on their funding. A surprisingly large number of administrators (including those who reported that they engage in advocacy) believed that policy advocacy is not effective $(32.7 \%, N=114)$. They felt that this belief hinders significant investment of time and resources on their part to advocacy efforts. Finally, lack of support from within the organization (board members and consumers) $(21.3 \%, N=74)$, lack of qualified staff $(21.3 \%, N=74)$, and lack of support from peers $(11.2 \%, N=39)$ in the field were also highlighted as other critical barriers (see Table 2).

TABLE 2

Most Common Barriers to Engaging in Advocacy

\begin{tabular}{lcc}
\hline Most common barriers & $N$ & $\%$ \\
\hline Lack of knowledge/awareness of issues & 214 & 61.5 \\
Lack of experience in policy advocacy & 194 & 55.7 \\
Lack of support from funding sources & 181 & 52.2 \\
Alienate funders & 129 & 37.1 \\
Belief that policy advocacy is not effective & 114 & 32.7 \\
Lack of interest & 111 & 31.9 \\
Lack of support from within the organization & 74 & 21.3 \\
Lack of support from staff & 74 & 21.3 \\
Lack of support from peers & 39 & 11.2 \\
\hline
\end{tabular}




\section{Policy Advocacy Techniques}

The most popular methods of advocating in the community included participating in community meetings or coalitions $(77.9 \%, N=271)$, contacting a local, state or national legislators via letter $(68.4 \%, N=238)$ or telephone $(66.4 \%, N=231)$, inviting legislators to visit the senior center $(60.3 \%, N=210)$, and attending public hearings $(66.1 \%, N=230)$. Approximately half of all senior center administrators stated that they had met in person with their elected representative on at least one occasion in the past year in order to discuss their concerns or needs $(52.9 \%$, $N=184$ ). Less than a third of all senior center administrators reported that they had attended a Town Hall meeting or a legislative hearing that was related to their service or funding issues $(30.2 \%, N=105)$. Few administrators had ever organized a community meeting to discuss policy issues $(31.3 \%, N=109)$ or written a newspaper editorial to highlight their concerns $(16.4 \%$, $N=57)$.

The most common methods of communicating with elected officials were e-mails $(81.6 \%$, $N=284)$, letter writing $(83.4 \%, N=290)$, and addressing community meetings $(77 \%$, $N=268$ ). The most frequent method of communicating with newspapers was press releases $(92.8 \%, N=323)$, interviews with reporters $(52.9 \%, N=184)$, and newsletters $(31.6 \%$, $N=110$ ). With respect to other forms of media, such as television and radio, very few administrators reported utilizing these for advocacy efforts. Of those respondents that did connect with media sources such as television or radio, they used press releases and occasional interviews (when invited) to communicate their concerns $(13.8 \%, N=48)$. It is critical to note that an even smaller proportion of administrators reported the use of electronic media such as the internet in their advocacy efforts $(3.7 \%, N=13)$. The most common methods of communicating with participants and their families were senior center newsletters, telephone contact, and informational sessions at the senior center.

As reported by the respondents, the most successful methods of advocating with legislators in terms of anticipated outcomes was personal meetings with legislators, as well as visits by the legislators to the senior center. Most respondents reported that they had the least amount of success with generating interest from commercial television and radio sources, other than a few public access shows. With respect to newspapers, the greatest success with respect to message dissemination was the development of personal relationships with reporters and human interest stories. Administrators reported minimal success or visibility with the use of press releases.

Approximately, one out of five senior center administrators reported utilizing professional lobbyists in their advocacy efforts $(20.7 \%, N=72)$. The minimum annual budget for the senior centers in this category was $\$ 1,000,000$. This may point to the significant costs incurred in retaining professionals for this purpose. Also, many senior centers with substantial government funding are prohibited from hiring professional lobbyists (see Table 3).

\section{Use of Policy Advocacy Information and Resources}

The National Council on Aging (NCOA) is a government-funded national organization that advocates for issues related to aging. It coordinates with other public agencies, elected representatives, private organizations, service, providers, consumers, and researchers to highlight the concerns and needs of older adults. The NCOA also maintains a web site that provides updated 
TABLE 3

Types of Advocacy Techniques

\begin{tabular}{lrr}
\hline Advocacy techniques utilized & $N$ & $\%$ \\
\hline I have attended a community meeting (e.g., neighborhood association, coalition meeting, etc.). & 271 & 77.9 \\
I have written a letter or e-mailed to a legislator or member of their staff. & 238 & 68.4 \\
I have called a legislator or member of their staff. & 231 & 66.4 \\
I have attended a public hearing organized by a legislature & 230 & 66.1 \\
I have invited a member of congress or their staff to my center. & 210 & 60.3 \\
I have visited a legislator or member of their staff in person. & 184 & 52.3 \\
I have organized a community meeting concerning a topic I care about. & 109 & 31.3 \\
I have attended a Congressional Town Hall meeting. & 105 & 30.2 \\
I have written a letter to the editor of a newspaper/newsletter. & 57 & 16.4 \\
I have written an opinion-editorial to a newspaper/newsletter. & 57 & 16.4 \\
DO NOT ENGAGE IN POLICY ADVOCACY OR PRACTICE & 40 & 11.5 \\
\hline
\end{tabular}

information on legislative policy issues that impact the lives of older adults and those that serve them. When asked if this resource was utilized, less than one third of all senior center administrators stated that they did $(31.6 \%, N=110)$. The most common reasons cited for nonutilization were lack of time, lack of awareness of the web site, and difficulty in accessing information quickly. An interesting comment made by several respondents who did utilize the web site was the critical need for practical training in advocacy and examples of effective techniques.

\section{Collaboration on Advocacy Efforts}

According to the OAA legislation, state offices and city departments of aging and the AAAs are required to collaborate with their constituents (individuals and organizations) to assess community needs, address service concerns, and develop a plan of action (funding for services) in a strategic, inclusive manner. OAA requires that AAAs and other offices seek the input of senior centers and other aging service providers in the annual plan development process (AoA, 2010; OAA, 2006). When queried if senior centers were asked to provide input in to the state plan, only a small proportion of senior centers and nutrition sites $(26.1 \%, N=91)$ reported collaborating in planning at the state level.

About one in four senior centers or nutrition sites $(39.1 \%, N=136)$ also provided input to their local area plan. However, the nature of input was sporadic and diverse. While some senior center administrators reported being asked to complete surveys or participate in focus groups, the majority of administrators stated that their input was limited to attending public hearings (scheduled when a completed plan would usually be introduced) where they could share their concerns or opinions about the proposed plan. Thus, the process of providing input was not considered comprehensive or sufficient by the respondents.

Overall, approximately half of all respondents reported collaborating with their local AAA $(47.1 \%, N=164)$ with reference to information/referrals or health promotion activities. Examples of collaborative initiatives provided were falls-prevention workshops, fitness interventions, mental health assessment, ombudsman program, health fairs, family caregiver support, homemaker services, Medicare enrollment, transportation access, volunteer services, and other health 
promotion initiatives. Most of these programs are funded through the OAA or other legislations, and the allocations are routed through the local AAA. There was minimal collaboration noted on any legislative policy issues Very few senior centers reported that they had been invited to serve on advisory councils established by the state offices of aging or by the local AAAs.

\section{DISCUSSION OF FINDINGS}

This study sheds light on critical issues related to policy advocacy by senior center administrators. Three themes emerged from the analysis: a lack of comprehensive collaboration and planning; the need for the integration of effective policy advocacy techniques into the day-to-day operations of senior centers; and a lack of adequate training in policy advocacy for administrators.

\section{A Need for a Comprehensive and Strategic Advocacy Plan}

The study revealed that although most senior centers engage in policy advocacy, their efforts are largely in response to impending crises. In other words, administrators use policy advocacy as a reactive stance or tactic when their agencies are faced with an immediate challenge to their financial wellbeing rather than on a proactive consistent basis. Administrators are not always knowledgeable of policy issues or pending legislations that might impact the lives of their consumers. These injudicious advocacy efforts risk appearing uncoordinated and unplanned leading to negative repercussions on the outcome of their advocacy efforts.

Most administrators also reported that they did not perceive much support from their peers in their advocacy efforts and that collaborations in advocacy activities were limited. This may be a consequence of competition between various service providers in one region who are all vying for support from the limited funding streams available in that community. Coupled with the concern expressed by several administrators that engagement in advocacy might alienate their funders, some administrators might shy away from advocacy collaborations. While administrators reported the involvement of a small but dedicated cadre of participants in their advocacy efforts, there was limited collaboration with other aging service providers (nonsenior centers) in any advocacy plans. Baker et al., (2001), Krout (1987), and Pardasani (2004c) have noted that strategic partnerships with community organizations, elected representatives, and stakeholders enhance the outcomes of any community organization or transformation efforts. As noted by DeVita et al. (2004), if social service agencies are to be effective in their advocacy efforts, they need to collaborate with a diverse array of active constituents, including consumers, community members, stakeholders, and organizations.

Finally, the extent of participation of senior centers in the development of state and local aging plans was relatively small. Even when administrators reported providing input on strategic plans, their participation was limited to commenting on already completed plans. Few administrators served on advisory councils or collaborated comprehensively in the development of these plans from the start (through focus groups, surveys, community meetings, etc.). Aday (2003b) and Krout (1998) have underscored the importance of senior centers working closely with policy makers and funding bodies to highlight the importance of senior centers to the aging continuum of care and their positive benefits for the communities they serve. It is critical that AAAs, state 
offices, and senior centers work collaboratively and strategically to ensure comprehensive planning and the funding of those services to meet the specific needs of their community.

\section{Integration of Effective Policy Advocacy Techniques}

Administrators of senior centers, nutrition sites, and AAAs identified several techniques use express their perspective on policy issues. They reported the use of letter-writing campaigns, e-mails, telephone calls to their elected representatives, and attending public hearings. In order to communicate with funders, constituents and stakeholders, they utilized newsletters, meetings with older adults, and letters to newspapers to highlight pressing issues. These more traditional techniques may not be the most sophisticated or effective.

The potential for success of these strategies is hampered by their limited relevance in this technological age. Hoefer (2002) and Teater (2009) identified knowledge of issues, timeliness, effective campaigns utilizing state-of-the-art technologies, building sustained relationships with decision makers, and coalitions with other interest groups as critical components of advocacy practice. Consistent communication with elected representatives is essential to building a long-standing trusting and productive partnership (DeVita et al., 2004; Donaldson \& Shields, 2009). However, in addition to telephone and written communication, administrators need to schedule regular meetings with legislators to update them on their needs, concerns, and issues. Legislators are bombarded by requests and demands from numerous constituents and have limited time to attend to all concerns. However, an on-going relationship with legislators and/or their aides would be beneficial for any advocacy efforts.

Social marketing techniques have illustrated the need for incorporating electronic technologies such as web sites, blogs, data mining and audio-visual media into impactful messaging plans (Andreasen, 1997). Only a few administrators in this study worked with television, radio, or newspapers in a strategic manner. Most resorted to old-fashioned press releases or letters which are often ignored. Cultivating relationships with media persons to create human interest stories and increase visibility in the community would be valuable to all advocacy efforts. Similarly, utilizing web-based technologies will expand the reach of organizations and help them influence untapped groups, agencies, and stakeholders. It is essential to remember that the aides (and interns) to most legislators and policy makers are from a generation most comfortable and proficient with these modern technologies.

\section{The Need for Education and Training on Policy Advocacy}

Researchers have highlighted the critical role played by leaders with reference to knowledge, skill, and motivation in guiding their organizations through policy advocacy (Donaldson \& Shields, 2009; Gibelman \& Kraft, 1996; Salamon, 1995; Saidel \& Harlan, 1998). Yet, most of the respondents identified a lack of awareness around major aging-related policy issues unless it impacted their funding directly. Concurrently, many administrators also reported that they had received limited training or education on policy advocacy in their educational programs. Few administrators, including those engaged in advocacy, were aware of the policy resources or best 
practice examples available to them. A few respondents also noted that they could not identify any programs or institutions that could provide cost-effective and time-limited training specific to their needs.

\section{IMPLICATIONS}

There are several implications for practice and education as evidenced by the findings of this study:

1. Senior centers need to create wide-ranging coalitions with diverse constituents to expand their advocacy efforts and ensure better outcomes. Additionally, by collaborating with other senior centers, administrators can share knowledge, effective techniques and their limited resources for greater impact.

2. Senior centers need to work closely with the aging establishment such as the AoA, state offices of aging, AAAs, and parks and recreation departments to create a strategic, coordinated plan for collaborative advocacy. This will ensure that the concerns of senior centers are at the forefront of all decision-making at the highest levels.

3. Administrators need to incorporate a wider array of techniques, including modern technologies, to ensure that their advocacy efforts reach out to a larger audience. Utilization of effective social marketing and sophisticated public relations campaigns will strengthen relationships with stakeholders and improve their chances for success. Given their limited budgets, senior centers could collectively pool their resources to finance large-scale advocacy efforts.

4. Administrators need substantive training in effective policy advocacy or practice techniques. Senior center associations could provide training or continuing education programs for administrators who are interested in enhancing their skills. Similarly, community coalitions could provide a venue for information-sharing, dialog, and consultation.

5. There needs to be a concerted effort for leadership development in senior centers. Such peer-led efforts could enhance the capacities of administrators to transform their senior centers.

6. Educational programs that prepare students for a career in gerontology need to enhance their curriculum to include content on policy issues related to aging and current advocacy techniques.

7. Organizations such as NCOA and the state associations could create a clearing house for best practice case examples, web-based training, and updated information on policy issues to empower and educate practitioners.

\section{LIMITATIONS}

This study, focusing specifically on policy concerns and the advocacy efforts of senior centers, is the first of its kind. Despite drawing from a national sample of senior center directors, there are some limitations to the generalizability of these findings.

Even though the researchers reached out to senior centers nationally, the outreach was limited to members of NISC and state associations. Since these administrators are already members of a 
state association or a national advocacy organization, they may be more oriented towards advocacy than a random sample of senior center administrators. Thus, the results may have been skewed by the self-selection of respondents in this study based on their professional interests. Similarly, the use of Survey Monkey for data collection may have prevented smaller senior centers (especially in rural areas) with limited Internet access from participating in the study. Future studies should expand the sample to a more diverse group of senior centers.

While the study asked respondents to identify various advocacy techniques, they were not asked about the outcome of their efforts. Assessing effectiveness would have yielded more in-depth information on the training needs of administrators. Lastly, the survey instrument was developed by the authors in collaboration with senior center administrators and the staff of NCOA. It is possible that the biases of the partners may have influenced the construction of the survey questions.

\section{CONCLUSION}

As senior centers continue to respond to the rapidly changing service-delivery environment in aging, they are faced with the challenge of innovating and transforming themselves. As focal points of service delivery, they have had a major impact on the lives of the older adults and the communities they serve. However, in order to remain relevant, they need to adopt newer and more effective practices in policy advocacy. These changes are essential if senior centers are to succeed in transmitting their messages, highlighting their concerns, and affecting change. It is hoped that this study can lead to greater dialog on the importance of effective and transformative policy advocacy.

\section{REFERENCES}

Aday, R. H. (2003a, March). Identifying important linkages between successful aging and senior center participation. Paper presented at the Joint Conferences of The National Council on Aging/American Society on Aging, Chicago, IL.

Aday, R. H. (2003b, May). Evolving role of the senior center in the 21st century. Written statement for the US Special Senate Committee on Aging.

Administration on Aging. (2000). Supportive services and senior centers program. Washington, DC: Department of Health and Human Services. Retrieved from http://www.aoa.gov/AoARoot/AoA_Programs/HCLTC/supportive_ services/index.aspx

Administration on Aging. (2010). Statement of organization, functions and delegations of authority. Washington, DC: Department of Health and Human Services. Retrieved from http://www.aoa.gov/aoaroot/about/Organization/docs/ AoA_Organizational_Statement

Andreasen, A. R. (1997). Marketing social change: Changing behavior to promote health, social development, and the environment. San Francisco, CA: Jossey-Bass.

Avner, M. (2002). The lobbying and advocacy handbook for nonprofit organizations. St. Paul, MN: Amherst H. Wilder Foundation.

Baker, P., Leitner, J., \& McAuley, W. J. (2001). Preparing future aging advocates: The Oklahoma Aging Advocacy Leadership Academy. The Gerontologist, 41(3), 394-400.

Caslyn, R., \& Winter, J. (1999). Who attends senior centers? Journal of Social Service Research, 26(2), 53-69.

Cohen, E. S. (2004). Advocacy and advocates: Definitions and ethical dimensions. Generations, 28(1), 9-16.

Congressional Research Services (CRS). (2008). Older Americans Act: FY2008 Funding and FY2009 Budget Request. CRS Report for Congress, March 27, 2008. Order Code: RL33880. 
Demko, D. (1979). Utilization, attrition, and senior center. Journal of Gerontological Social Work, 2, 87-93.

De Vita, C., Mosher-Williams, R., \& Stengel, N. (2001). Nonprofit organizations engaged in child advocacy. In C. De Vita \& R. Mosher-Williams (Eds.), Who speaks for America's children? (pp. 3-38). Washington, DC: Urban Institute Press.

De Vita, C., Montilla, M., Reid, B., \& Fatiregun, O. (2004). Organizational factors influencing advocacy for children. Washington, DC: Urban Institute Press.

Donaldson, L. P. (2007). Advocacy by nonprofit human Service Agencies: Organizational factors as correlates to advocacy behavior. Journal of Community Practice, 15(3), 139-158.

Donaldson, L. P., \& Shields, J. (2009). Development of the Policy Advocacy Behavior Scale: Initial reliability and validity. Research on Social Work Practice, 19(1), 83-92.

Gibelman, M., \& Kraft, S. (1996). Advocacy as a core agency program: Planning considerations for voluntary human service agencies. Administration in Social Work, 20(4), 43-59.

Harris, L., \& Associates. (1975). The myth and reality of aging in America. Washington, DC: The National Council on the Aging.

Hoefer, R. (2002). Political advocacy in the 1980s: Comparing human services and defense interest groups. The Social Policy Journal, 1(1), 99-112.

Krout, J. (1982). Determinants of service use by the aged. Final report to the AARP Andrus Foundation. Freedonia, NY: Author.

Krout, J. (1984). The utilization of formal and informal support by the aged: Rural vs. urban differences. Final report to the AARP Andrus Foundation. Freedonia, NY: Author.

Krout, J. (1987). Senior center linkages and provision of services to the elderly. Final report to the AARP Andrus Foundation. Freedonia, New York: Author.

Krout, J. (1988). The frequency, duration, stability, and discontinuation of senior center participation: Causes and consequences. Final report to the AARP Andrus Foundation. Freedonia, NY: Author.

Krout, J. (1994). Changes in senior center participant characteristics during the 1980s. Journal of Gerontological Social Work, 22(1/2), 41-60.

Krout, J. (1998). Senior centers in America (5th ed.). New York, NY: Greenwood.

Leanse, J., \& Wagener, L. (1975). Senior centers: A report of senior group programs in America (p. 29). Washington, DC: The National Council on the Aging.

Leest, L. (1995). Senior centers and life satisfaction. (Unpublished doctoral dissertation). Yeshiva University, New York, NY.

Lun, W. (2004). The effects of race and gender on predicting in-home and community-based service use by older adults. Research in the Sociology of Healthcare, 22, 121-139.

Mickelson, J. S. (1995). Advocacy. In Encyclopedia of Social Work (19th ed., pp. 95-100). Washington, DC: National Association of Social Workers.

Mitchell, J. (1995). Service awareness and use among older North Carolinians. Journal of Applied Gerontology, 14(2), 193-209.

National Association of State Units on Aging. (2008). Project 2020: Building on the promise of home and community-based services. Retrieved from www.n4a.org/pdf/transition_memo_letterhead_dec_08.pdf

National Council on Aging. (2009). NCOA issue brief: Older Americans Act appropriations. Retrieved from http:// www.ncoa.org/assets/files/pdf/IB10-OAA-Approps.pdf

National Council on Aging. (2010a). Older Americans Act appropriations. Retrieved on from http://www.ncoa.org/ assets/files/pdf/OAA-Appropriations-10-august-1.pdf

National Council on Aging. (2010b). Senior centers: 2011 Older Americans Act reauthorization. Retrieved from http:// www.ncoa.org/assets/files/pdf/NCOA-OAA-Reauthorization-Senior-Centers-Concept-Paper.pdf

National Institute of Senior Centers. (2010). Senior centers fact sheet. Washington, DC: Author. Retrieved from http:// www.ncoa.org/press-room/fact-sheets/senior-center-fact-sheet.html

Netzer, J., Coward, R., Peek, C., Henretta, J., Duncan, R., \& Dougherty, M. (1997). Race and residence differences in the use of formal services by older adults. Research on Aging, 19(3), 300-332.

Older Americans Act. (2006). Public Law 109-365. Amended on October 7, 2006.

Pardasani, M. (2004a). Senior centers: Increasing minority participation through diversification. Journal of Gerontological Social Work, 43(2/3), 41-56.

Pardasani, M. (2004b). Senior centers: Patterns of programs and services. Activities, Adaptation \& Aging, 28(4), $27-44$. 
Pardasani, M. (2004c). Senior centers: Patterns of programs and services (Unpublished doctoral dissertation). Yeshiva University, New York, NY.

Pardasani, M. (2010). Senior centers: Characteristics of participants and nonparticipants. Activities, Adaptation \& Aging, 34(1), 48-70.

Pardasani, M., Thomspon, P., \& Sporre, K. (2009). New Models Taskforce: Final report. Washington, DC: National Institute of Senior Centers. Retrieved from http://www.ncoa.org/strengthening-community-organizations/seniorcenters/nisc/nisc-research.html

Pardasani, M., Sackman, B., \& Jellinek, I. (2010). $21^{\text {st }}$ century senior centers: Changing the conversation. Retrieved from http://www.cscs-ny.org/files/Report-for-Website.pdf

Ralston, P. (1982). Perceptions of senior centers by the Black elderly: A comparative study. Journal of Gerontological Social Work, 4(34), 127-137.

Ralston, P. (1983). Levels of senior centers: A broadened view of group based programs for the elderly. Activities, Adaptation and Aging, 3, 79-91.

Ralston, P. (1984). Senior Center utilization by Black elderly adults: Social, attitudinal and knowledge correlates. Journal of Gerontology, 39, 224-229.

Ralston, P. (1991). Senior Centers and minority elders: A critical review. The Gerontologist, 31(3), 325-331.

Saidel, J., \& Harlan, S. (1998). Contracting and patterns of nonprofit governance. Nonprofit Management and Leadership, 8(3), 243-259.

Salamon, L. (1995, March). Exploring nonprofit advocacy. Paper presented at the Independent Sector Spring Research Forum, Alexandria, VA.

Schneider, R., \& Lester, L. (2001). Social work advocacy. Belmont, CA: Wadsworth.

Strain, L. (2001). Senior Centers: Who participates? Canadian Journal of Aging, 20(4), 471-491.

Teater, B. (2009). Influencing state legislators: A framework for developing effective social work interest groups. Journal of Policy Practice, 8(1), 69-86.

The Center on Philanthropy at Indiana University. (2010). U.S. charitable giving falls 3.6 percent in 2009 to $\$ 303.75$ billion [press release, June 9, 2010]. Retrieved from http://www.philanthropy.iupui.edu/news/2010/06/prGUSA2010.aspx

Tuckman, J. (1967). Factors related to attendance in a center for older people. Journal of American Geriatrics Society, $15,474-479$.

U.S. Census Bureau. (2010). The next four decades: The older population in the United States: 2010-2050 (Document \# P25-1138). Washington, DC: US Department of Commerce. Retrieved from http://www.census.gov/prod/2010pubs/ p25-1138.pdf 